\title{
DNA rearrangements generating artificial promoters
}

\author{
A.I. Gragerov, O.Yu. Smirnov, S.L. Mekhedov, V.G. Nikiforov, S.A. Chuvpilo* and V.G. \\ Korobko* \\ Institute of Molecular Genetics, USSR Academy of Sciences, Kurchatov sq.46, 123182 Moscow and *Shemyakin \\ Institute of Bioorganic Chemistry, USSR Academy of Sciences, Vavilov street 32, 117988 Moscow, USSR
}

Received 19 April 1984

\begin{abstract}
The promoter-cloning plasmid pBRH4 (a derivative of pBR322 with a partially deleted promoter of the tet gene) is shown to contain a sequence which is located near the EcoRI site and can operate as an effective Pribnow box, but is not the remainder of the deletion-inactivated tet promoter of pBR322. If there is a sequence homologous to the ' -35 ' promoter region at the border of the DNA fragment inserted at the EcoRI site, then a compound promoter arises and activates the tet gene. Point mutations in the nonfunctional - 35 region of pBRH4 also activate the cryptic Pribnow box. Several compound promoters were obtained through deleting small portions of DNA around the HindIII site of pBR322; the deletions moved various sequences that could operate as Pribnow boxes towards the -35 region of the tet promoter.
\end{abstract}

$$
\text { Pribnow box '-35' region S1-mapping }
$$

\section{INTRODUCTION}

Several plasmids with a partially deleted promoter of the tetracycline resistance gene have been used for promoter cloning [1-3]. It has already bcen noted that the activation of the tet gene does not always indicate the presence of the natural promoter in the inserted fragment but may reflect an incidental fit of the end of the fragment and the remainder of the tet gene promoter giving rise to a compound promoter [3]. This property of the pBRH4 plasmid, which makes it an imperfect vector for promoter cloning, has been used here to generate artificial promoters.

\section{MATERIALS AND METHODS}

Plasmids were isolated as in [4].

DNA was sequenced as in [5] as modified in [6].

Deletions in pBR322 were obtained through treatment of a HindIII-linearized plasmid $(2 \mu \mathrm{g})$ with 5 units $S 1$ nuclease in $100 \mu$ l of $100 \mathrm{mM} \mathrm{NaCl}$, $3 \mathrm{mM} \mathrm{ZnSO}, 30 \mathrm{mM}$ sodium acetate (pH 4.8) for 10-30 min at $20^{\circ} \mathrm{C}$. The resulting DNA after blunt-end ligation was used to transform $E$. coli
HB101 cells, then ampicillin resistant clones were selected and tested for tetracycline resistance.

Mutations that activate the tet gene were obtained either by selecting spontaneously arising Tet $^{\mathrm{R}}$ clones of $E$. coli $\mathrm{C} 600$ (pBRH4) or through treatment of these cells with $10 \mu \mathrm{g} / \mathrm{ml} N$-nitro$N^{\prime}$-nitrosoguanidine.

The Mspl fragment of pBR322, which contains the tet gene promoter, was used for the S1-mapping of transcription starting points. The fragment was labelled at the $5^{\prime}$-end with $\mathrm{T} 4$ polynucleotide kinase [5], cleaved with BspRI, then the large subfragment was isolated. RNA extraction and S1 mapping were carried out as in [7] with the following modifications: during S1 treatment $\mathrm{NaCl}$ was added to $500 \mathrm{mM}$, the duration of treatment was reduced to $5 \mathrm{~min}$ and the temperature was $20^{\circ} \mathrm{C}$.

\section{RESULTS AND DISCUSSION}

The plasmid pEG3503, obtained earlier through inserting the EcoRI-G fragment of the $r p o \mathrm{BC}$ operon into pBRH4 [8], makes cells resistant to $20 \mu \mathrm{g} / \mathrm{ml}$ tetracycline despite the fact that the pro- 
moter contained in the EcoRI-G fragment was reported to be weak $[9,10]$. To localize the promoter that caused tetracycline resistance, the transcription initiation point was determined by the $\mathrm{S} 1$ mapping experiments. The transcription of the tet gene in pEG3503 containing cells was shown to be initiated near the border of pBRH4 and the inserted fragment (see fig.1,2). One can see that the Pribnow box, which does not coincide with the Pribnow box of the pBR322 tet promoter, belongs to $\mathrm{pBRH} 4$, and the -35 region belongs to the fragment of the rpoBC operon which normally encodes

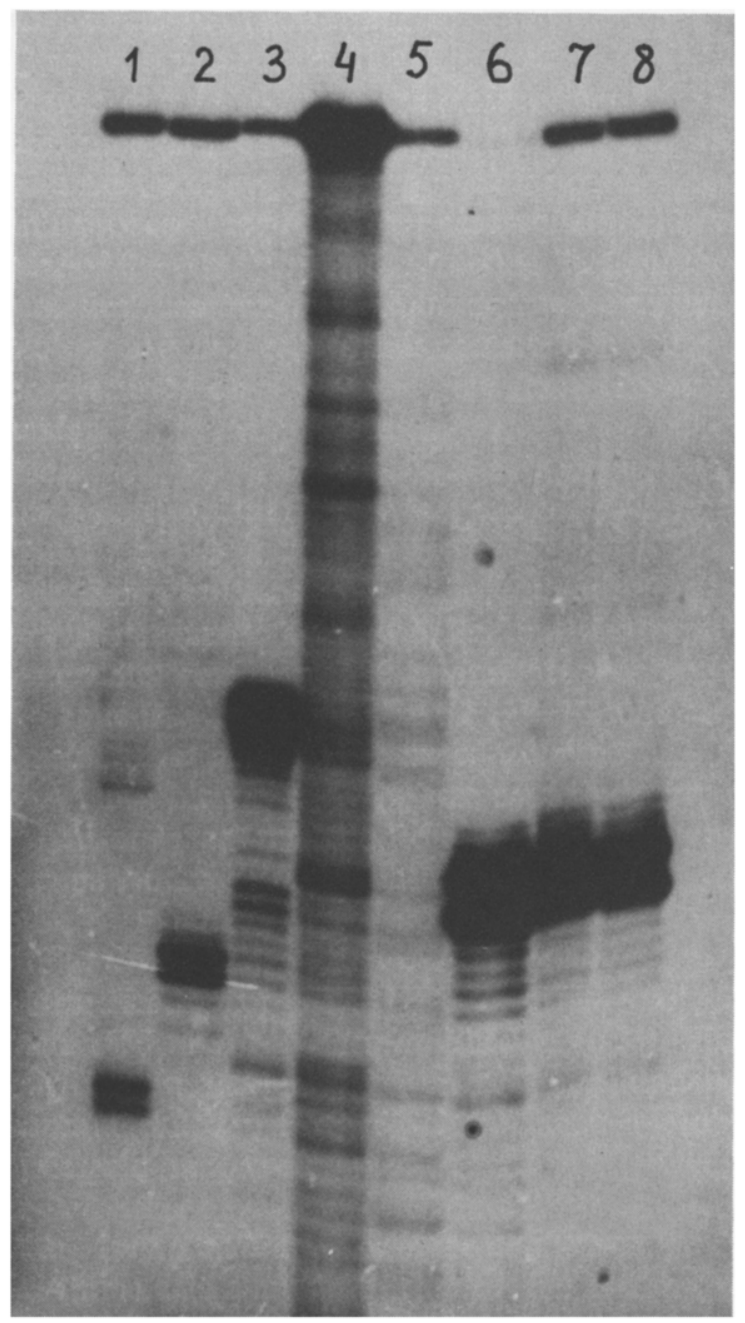

Fig.1. S1-mapping of 5'-ends of plasmid transcripts: 1, pBR $\Delta 22 ; 2, \operatorname{pBR} \Delta 15 ; 3, \operatorname{pBR} 322 ; 6, \operatorname{pBR} \Delta 10 ; 7$, pEG3503; 8, pBRH4-25; 4,5, DNA fragments obtained as in [5] and used as $M_{\mathrm{r}}$ markers. the amino acids of the $\beta$-subunit of RNA polymerase.

The tet gene does not work in pBRH4 without the insertion, even though there is a Pribnow box, i.e., the sequence occupying the $-\mathbf{3 5}$ position is not functional. However, $\mathrm{pBRH} 4$ gives rise to mutants which sustain cell growth on $20 \mu \mathrm{g} / \mathrm{ml}$ tetracycline with a spontaneous frequency of $10^{-8}$ and a nitrosoguanidine-induced frequency of $10^{-5}-10^{-4}$. The S1 mapping of 1 spontaneous and 6 nitrosoguanidine-induced mutant variants of pBRH4 (fig.1 shows the data for one of them) revealed one starting point in all cases, the same as in pEG3503, i.e., the same Pribnow box as in the above described compound promoter operates here. One of the nitrosoguanidine-induced pBRH4 mutants (pBRH4-25) has been sequenced. As shown in fig. 2 , the mutation substitutes $\mathrm{T}$ for $\mathrm{C}$ at position -34 from the starting point, i.e., creates a functional -35 region.

These results show that when there is a readymade Pribnow box it is easy enough to select a sequence that will function as a -35 region. That is what happened in the case of pEG3503 and, presumably, in other cases when artifacts were observed during cloning in pBRH4. A similar situation may be expected to arise when there is a ready-made -35 region and various sequences are fitted to it. To test this supposition, we obtained several deletion derivatives of pBR322 with an 'ideal' sequence in the -35 region of the tet promoter. Deletions were obtained in the vicinity of the HindIII site (see section 2). After transforma-

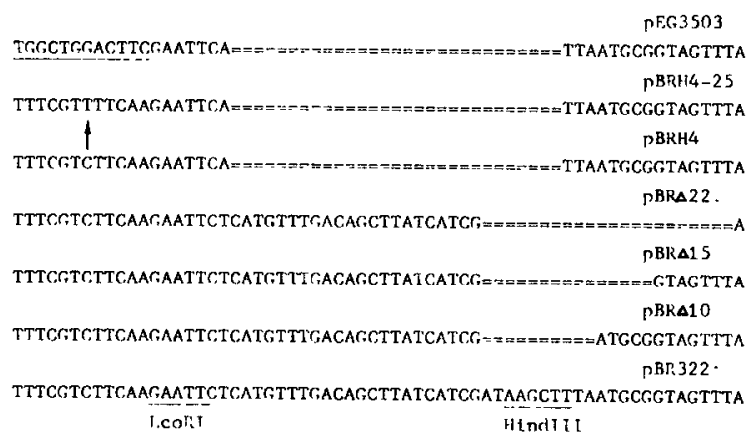

Fig.2. Mutation changes in the sequence preceding the tet gene. $=$, deleted nucleotides. The point mutation in pBRH4-25 is indicated by an arrow. The bacterial insertion in pEG3503 and the EcoRI and HindIII restriction sites are underlined. 
tion we selected 3 clones containing deleted plasmids and having different levels of tetracycline resistance. Plasmid sequences are shown in fig.2. In accordance with the deletion length, they are denoted pBR $\Delta 10, \mathrm{pBR} \Delta 15$ and $\mathrm{pBR} \Delta 22$. The $\mathrm{S} 1$ mapping of these plasmids (fig. 1) has shown, as expected, that one and the same -35 region operates in all 3 cases and the promoters differ in their Pribnow boxes. The pBR $\Delta 10$ plasmid, which has a stronger tet promoter than pBR322, proved to have the same transcription starting point, hence the same Pribnow box, as pEG3503 and the pBRH4 mutants with an activated tet gene. In pBR $\Delta 15$ and pBR 222 the tet promoter is not very effective, but at least in pBR $\Delta 22$ nitrosoguanidine induces mutations (approximate frequency $10^{-7}$ ) which increase the promoter efficiency several times.

Our results show that a promoter arises with comparative ease if either of its 'halves' is already present. By fitting to it various DNA sequences to recreate a whole promoter one can, in principle, construct many artificial promoters. The process may also occur naturally. For example, it was in this way that a promoter appeared in the gal operon on the insertion of the IS2 element [11].

Our data allow the efficiency and the sequence to be compared for 7 variants of the tet promoter: 4 promoters have the same -35 region but different Pribnow boxes (pBR322, pBRA10, pBR $\Delta 15$ and pBR $\triangle 22$ ), and 4 variants have the same Pribnow box but different -35 sequences (pEG3503, pBR $\Delta 10$, pBRH4 and pBRH4-25). Fig. 3 shows the promoter sequences and summarizes the efficiency data. Promoter efficiency was evaluated by the level of tetracycline resistance of cells carrying the plasmid concerned and by the amount of nucleaseresistant DNA fragments in S1 mapping experiments (the two methods correlate quite well). The relation between the efficiency of these promoters and their sequence is discussed at length elsewhere.

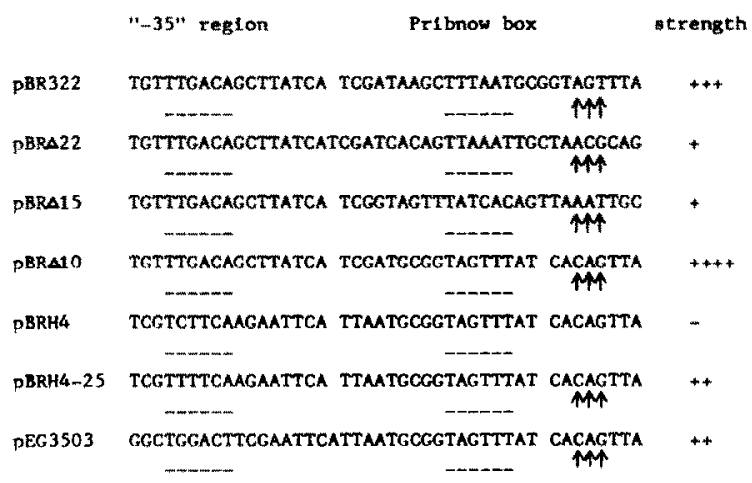

Fig.3. Mutant tet promoter sequences. The sequences are aligned with respect to their functionally important parts. Positions of the $\mathrm{S} 1$ nuclease cleavage sites are shown by arrows. + , the qualitative level of promoter efficiency.

\section{REFERENCES}

[1] An, G. and Friesen, J.D. (1979) J. Bacteriol. 140, 400-407.

[2] West, R.W., Neve, R.L. and Rodriguez, R.L. (1979) Gene 7, 271-288.

[3] West, R.W. and Rodriguez, R.L. (1982) Gene 20, 291-304.

[4] Birnboim, H.C. and Doly, J. (1979) Nucleic Acids Res. 7, 1513-1523.

[5] Maxam, A.M., Gilbert, W. (1980) in: Methods in Enzymology (Grossman, L. and Moldave, K. eds) Nucleic Acids, vol.65, part 1, pp.499-560, Academic Press, New York.

[6] Chuvpilo, S.A. and Kravchenko, V.V. (1983) Bioorg. Khim. (USSR) 9, 1634-1638.

[7] Aiba, H., Adhya, S. and De Crombrugghe, B. (1981) J. Biol. Chem. 256, 11905-11910.

[8] Bass, I.A., Kurenova, E.V. and Mekhedov, S.L. (1982) Mol. Biol. (Moscow) 16, 575-580.

[9] Holowachuk, E.W., Friesen, J.D. and Fiil, N.P. (1980) Proc. Natl. Acad. Sci. USA 77, 2124-2128.

[10] Barry, G., Squires, C.L. and Squires, C. (1979) Proc. Natl. Acad. Sci. USA 76, 4922-4926.

[11] Hinton, D.M. and Musso, R.E. (1982) Nucleic Acids Res. 10, 5015-5031. 